University of South Carolina

Scholar Commons

8-3-2012

\title{
The Role of Individual Behavior Type in Mediating Indirect Interactions
}

\author{
Blaine D. Griffen \\ University of South Carolina - Columbia, bgriffen@biol.sc.edu \\ Benjamin J. Toscano \\ University of South Carolina - Columbia \\ John Gatto \\ University of South Carolina - Columbia
}

Follow this and additional works at: https://scholarcommons.sc.edu/biol_facpub

Part of the Biology Commons, and the Marine Biology Commons

\section{Publication Info \\ Published in Ecology, ed. J. J. Stachowicz, Volume 93, Issue 8, 2012, pages 1935-1943. \\ (c) Ecology 2012, Ecological Society of America.}

This Article is brought to you by the Biological Sciences, Department of at Scholar Commons. It has been accepted for inclusion in Faculty Publications by an authorized administrator of Scholar Commons. For more information, please contact digres@mailbox.sc.edu. 


\title{
The role of individual behavior type in mediating indirect interactions
}

\author{
Blaine D. Griffen, ${ }^{1,2,3}$ Benjamin J. Toscano, ${ }^{1}$ and John Gatto ${ }^{2}$ \\ ${ }^{1}$ Department of Biological Sciences, University of South Carolina, Columbia, South Carolina 29208 USA \\ ${ }^{2}$ Marine Science Program, University of South Carolina, Columbia, South Carolina 29208 USA
}

\begin{abstract}
Trait-mediated indirect interactions (TMII) play an important role in structuring natural communities, and numerous studies have experimentally demonstrated their presence in a variety of systems. However, these studies have largely examined the presence or absence of traits that are responsible for these interactions, without considering natural variation between individuals in the extent to which these traits are manifested. We used a well-documented TMII to investigate the importance of individual behavior type for determining the strength of the TMII. The toadfish Opsanus tau has an indirect positive influence on bivalve survival because the mud crab Panopeus herbstii, a consumer of bivalves, reduces foraging effort in the presence of toadfish. We quantified variation in the strength of persistent individual mud crab responses to toadfish and resulting variation in the strength of TMII. We demonstrate that the strength of this TMII is strongly influenced by mud crab size and behavior type, strengthening with the intensity of response of individual mud crabs to toadfish predator cues. Further, we demonstrate that the spatial distribution within intertidal oyster reefs of crabs with different behavior types is not random; mud crabs inhabiting subtidal areas, where predator cues are more persistent, are significantly less responsive to toadfish cues than mud crabs from intertidal areas. This spatial behavioral structure should lead to spatial variation in the strength of TMII. Given the widespread importance of TMII and the broad occurrence of individual personality or behavior types across numerous taxa, these results should be generally applicable. The distribution of behavior types within a population may therefore be a useful metric for improving our ability to predict the strength of TMII.
\end{abstract}

Key words: behavioral effects; individual variation; personality; trait-mediated indirect effects.

\section{INTRODUCTION}

Indirect biotic interactions occur when one species influences a second via its interactions with a third species. Indirect interactions are common (e.g., Wootton 1994), play a crucial role in structuring marine (Menge 1995), freshwater (Kerfoot and Sih 1987), and terrestrial (Rosenheim 1998) ecological communities, and can propagate through ecological communities in two ways: by changes in species densities because of direct consumption, and by changes in species traits (i.e., trait plasticity), such as behavior, morphology, or physiology. Several terms have been used to describe this second group of indirect interactions that are propagated via species' traits. Following Abrams (2007), we refer to these as trait-mediated indirect interactions, or TMII. Further, while TMII may be propagated via numerous behavioral, morphological, or physiological traits, we focus here on indirect effects propagated via behavioral traits alone.

Manuscript received 30 November 2011; revised 9 March 2012; accepted 20 March 2012. Corresponding Editor: J. J. Stachowicz.

${ }^{3}$ E-mail: bgriffen@biol.sc.edu
Hundreds of studies over more than two decades document various types of TMII, including top down effects in linear interaction chains (e.g., Wissinger and McGrady 1993), bottom up effects in linear interaction chains (e.g., Anholt and Werner 1995), interactions with multiple predators that share the same prey (Sih et al. 1998), interactions with multiple prey that share the same predator (e.g., Toscano et al. 2010), and numerous other more complex interaction webs (Werner and Peacor 2003). Reviews of these TMII and their roles in ecological communities have concluded that they are pervasive and that they provide an important community-structuring force, with effects equivalent to, if not greater than, indirect interactions transmitted through changes in density (Bolker et al. 2003, Werner and Peacor 2003, Schmitz et al. 2004, Luttbeg and Kerby 2005, Preisser et al. 2005).

Given the importance of TMII in ecological communities, a major goal in ecology is to elucidate the factors that determine the strength and variation in TMII, so that community dynamics can be predicted from a mechanistic understanding of community components. Toward this goal, recent studies have focused not just on documenting the occurrence of TMII, but on determining the environmental and biological factors that control 
their strength and importance relative to other community-structuring factors. For example, recent studies demonstrate that TMII vary with such factors as habitat complexity (e.g., Griffen 2006, Grabowski et al. 2008), resource identity (Trussell et al. 2008), predator hunting mode (Schmitz and Suttle 2001), and species density (Griffen and Williamson 2008). Increased understanding of such contributing factors improves our ability to predict the outcome of complex interactions. However, while previous studies have successfully predicted effects of TMII qualitatively (e.g., Relyea and Yurewicz 2002), quantitative predictions have been more elusive, as traitmediated interactions often yield emergent effects that are different from what is expected based on mean individual interactions. This residual uncertainty comes from contributing factors not yet identified.

One potentially contributing factor that has received broad attention outside the realm of TMII research is individual trait variation. Variation between individuals within a population is common for ecological traits, and recent reviews have highlighted this variation in numerous individual traits, including food and habitat preferences (Bolnick et al. 2003), morphology (Bolnick et al. 2007), physiology (Careau et al. 2008), and behavior (Sih et al. 2004a). Individual variation is central to basic ecological and evolutionary processes. For example, individual variation is one of the primary determinants of population stability (Lomnicki 1988) and thus extinction risk (Connor and White 1999, Fox and Kendall 2002, Kendall and Fox 2002, 2003, Fox 2005, Vindenes et al. 2008). Additionally, individual variation provides the raw material for evolutionary selection and populations with more individual variation may therefore experience evolutionary diversification more readily (Rosenzweig 1978, Wilson and Turelli 1986, Doebeli 1996, Dieckmann and Doebeli 1999). Finally, the presence of intraspecific trait variation is important not only for population level processes like extinction and evolution, but can also influence community interactions (Bolnick et al. 2011). Thus, individual variation is often one of the most important things that we measure in ecological studies. However, despite the central importance of individual variation in ecological and evolutionary processes, it is often ignored and deference is given instead to testing dissimilarity among mean values (i.e., "the tyranny of the golden mean" [Bennett 1987]). In TMII studies where behavior is the trait responsible for propagating an indirect effect, it is often implicitly assumed that all individuals in the population display the trait to the same degree. For example, a common type of TMII in a three-species food chain is a positive indirect impact of predators on basal resources by causing prey to alter their foraging to avoid predation risk (Werner and Peacor 2003). Studies that have documented these indirect interactions have largely ignored differences in the strength of this behavioral response across individual prey within the population.
Finally, prey species often shift habitats in response to predation risk, moving from risky habitats to habitats that provide enhanced protection from predators. These shifts can themselves be the trait that propagates TMII, as prey resources in the risky habitat receive a positive indirect benefit from predator presence (reviewed in Schmitz et al. 2004). In addition, when prey utilize multiple habitat types and respond to predation risk not by shifting habitats, but by reducing activity levels, habitats that provide different levels refuge from predation can result in habitat-specific strengths of TMII (e.g., Griffen and Byers 2006). Despite the prevalence of habitat shifts or habitat selection by prey in response to predation risk, a population of prey often does not shift habitats en masse. Rather, individuals that are more risk averse may choose to remain in riskier, and more energetically profitable, habitats. In this case, we may expect to find a physical separation of behavior types between habitats that could ultimately lead to spatial differences in the strength of TMII, independent of the influence of refuge quality of different habitats.

Behavioral differences between individuals are widespread throughout taxonomic groups, rather than an exceptional case (Gosling 2001). It is therefore somewhat surprising that this individual variation has not yet been included in studies of indirect effects in an effort to explain more of the experimental variation, particularly given the importance of individual behavior variation in two species predator-prey interactions (Sih et al. 2004a). Here we investigate the role of behavioral variation in determining the strength of trait-mediated indirect interactions in a simple linear food chain.

\section{Methods \\ Study system}

We examined a simple food web that is common to intertidal salt marsh ecosystems along the southeast and Gulf coasts of North America. This system consists of a linear food chain that includes the toadfish Opsanus tau as top predator, the mud crab Panopeus herbstii as intermediate predator, and the scorched mussel Brachidontes exustus as prey. Each of these species is commonly found inhabiting oyster reefs.

Toadfish are abundant, nonmigratory, benthic fish that are common to oyster habitats along the Atlantic Coast (Gudger 1910). This species primarily consumes crabs (Gudger 1910), with mud crabs comprising approximately $77 \%$ of its diet in South Carolina (Wilson et al. 1982). Ecological theory predicts that TMII will dominate in systems with sit-and-wait (ambush) predators such as the toadfish (Schmitz et al. 2004), and this prediction is supported by previous studies in this system. Mud crabs strongly reduce activity levels and feeding rates in the presence of toadfish, (Grabowski and Kimbro 2005), creating a positive indirect effect on bivalve survivorship (Grabowski 2004, Grabowski et al. 2008). Overall, $>95 \%$ of the total indirect benefit to bivalve prey from toadfish comes not from direct 
consumption of mud crabs, but from reduced mud crab foraging as a response to predation risk (Grabowski 2004). In other words, TMII are the predominant force in this simplified food web. Finally, trophic interactions in this system are strongly influenced by oyster reef habitat complexity (Grabowski 2004, Grabowski and Powers 2004, Grabowski et al. 2008); yet strong behavioral effects resulting in TMII persist in this system, regardless of the strength of actual consumptive effects. Thus, TMII account for $>95 \%$ of indirect effects in low complexity reefs where predation is stronger, while they account for $>98 \%$ of indirect effects in more complex reefs where direct predation is weaker (Grabowski 2004).

\section{Refuge use in the presence and absence of predator cues}

We conducted an experiment to measure the proportion of time that individual crabs spent foraging vs. hiding in refuge in the presence and in the absence of toadfish predator risk cues. Crabs for this experiment ( $n$ $=48$, males and females $>30 \mathrm{~mm}$ carapace width) were collected from intertidal oyster reefs in North Inlet, South Carolina, USA. Crabs were starved for $24 \mathrm{~h}$ and were then placed individually into separate 40-L flowthrough chambers $(n=6$, allowing for eight blocked trials through time). Each chamber contained $2 \mathrm{~cm}$ of sieved sediment under an $\sim 8 \mathrm{~cm}$ layer of dead oyster shell that was cleaned of all epibionts. Water that was supplied to these experimental chambers came from head tanks. Three experimental chambers were supplied with water that was free of risk cues, and three chambers were supplied with water from a head tank that housed a toadfish that was fed mud crabs, creating predator risk cues. Finally, we glued eight scorched mussels to the walls of the experimental chambers. Mussels were observed for $24 \mathrm{~h}$ following attachment to walls to ensure normal filter feeding activity. The desire to forage in crabs should depend on the level of satiation, and crabs with different behavior types may differ in the hunger thresholds that stimulate foraging under natural conditions, either in the presence or absence of predation risk. For simplicity, we therefore eliminated the potential for satiation to occur in our experiment and instead maintained hunger levels in order to stimulate foraging throughout the duration of each trial. We did this by placing mussels high enough on the wall that they could not be reached by mud crabs, but their presence created chemical cues that stimulated mud crab foraging behavior. Preliminary data indicated that mud crabs forage most actively at night. We therefore conducted all experimental trials at night under illumination from dim red lights to minimize disturbance of crabs (Griffen and Williamson 2008). We further ensured that observers did not disturb the crabs and alter behavior by placing the observer behind a screen made of black plastic.

Crabs were tested in blocks of six, each block taking two days to complete. Crabs were randomly assigned on the first night to the risk cue or the no risk cue treatment. The same crabs were then given the other trial on the subsequent night. All trials began at dusk. During trials, crabs were placed into experimental chambers and allowed 15 minutes before data collection began. At six-minute intervals for the next three hours, we recorded whether each crab was taking refuge under the layers of shell, or was actively moving on top of this refuge habitat. We then used the proportion of these 30 measurements that crabs were in the refuge (i.e., not visible) as the response variable for analysis. We examined whether behavior was consistent within individual crabs (i.e., whether crabs showed consistent behavior types) using Pearson's correlation (Pruitt et al. 2012). We then used linear models with a binomial error distribution to determine whether the proportion of time that crabs spent using refuge habitat was influenced by crab size. We conducted separate models analyses for crabs in the presence and absence of predator risk cues. These and all other analyses were conducted using $\mathrm{R}$ v.2.14.1 (R Development Core Team 2011). Ideally, our analysis would have combined measurements in the presence and absence of risk cues within a single analysis using a mixed effects model (Dingemanse et al. 2010). However, we could not use a mixed effects model because our binomial response variable was overdispersed, and accounting for overdispersion with the common approach of including an observation level random effect in the analysis would have obscured the effect of individual variation between crabs, which was the central question in this study.

\section{Effect of behavioral variation on TMII}

Following the experiment described in the last subsection, we used the same individual crabs to test the strength of the trait-mediated indirect effect of toad fish on scorched mussels, as a function of the proportion of time that mud crabs used the oyster shell refuge as determined from the previous experiment. This experiment was conducted over five nights, and was conducted for each crab on the nights following the conclusion of the experiment described above. We maintained the same treatment order in the two experiments (i.e., crabs either received no cue or received cue treatments first in both experiments). The experiment was set up in an identical manner to the experiment described above, except that 40 scorched mussels (15-25 mm shell length) were first allowed to attach naturally overnight using byssal threads to the oyster shells. Crabs were placed in the first treatment (either presence or absence of risk cue) and were allowed to forage for $48 \mathrm{~h}$. We assessed mussel consumption at the end of this time. We then starved crabs for $24 \mathrm{~h}$ to restandardize hunger, and then repeated the 48-h trial with each crab receiving the other risk cue treatment. We followed recommendations of Dingemanse et al. (2010) for simultaneously examining trait plasticity and intraspecific trait variation, and used mixed effects modeling. We analyzed the number of 


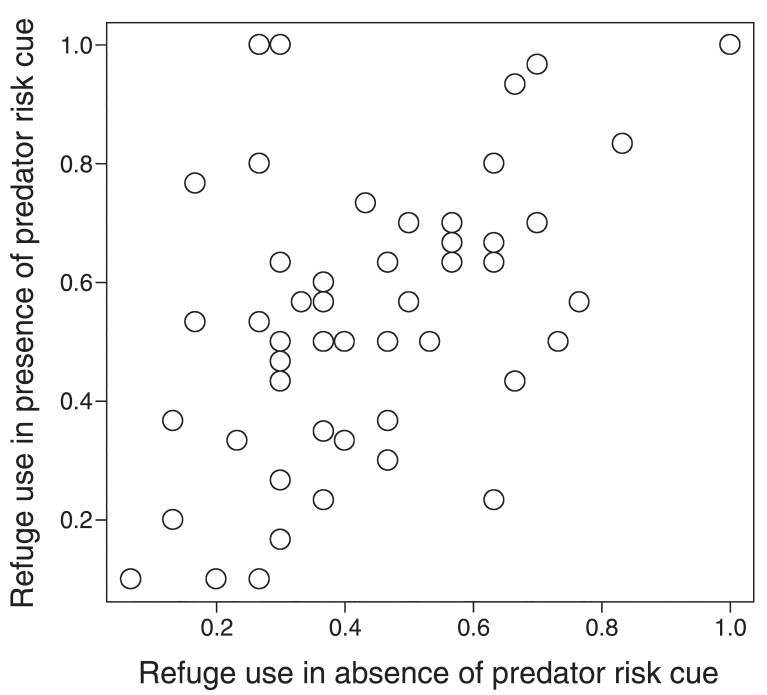

FIG. 1. Correlation between proportion of time spent in refuge in the presence and absence of predation risk cues by individual crabs.

mussels consumed using a linear mixed effects model with proportion of time in the refuge in the presence and absence of risk cues (from the previous experiment), respectively, and with risk cue presence/absence and crab size as fixed effects, and with crab ID number as a random effect. This analysis allowed us to pair for individual crabs the refuge use in the presence or absence of risk cues with consumption under those same conditions. Because the response variable (mussel consumption) was count data, we used a Poisson error distribution. The interaction term between the fixed effects was significant. Therefore, to aid in interpretation, we repeated the analysis for crabs in the presence or absence of risk cues separately. Once again, cue order and sex had no effect in the models and so were not included in final analyses.

\section{Behavior type and distribution in the field}

Finally, predation risk is not constant throughout the intertidal range. Rather, exposure to toadfish and to many other predators decreases with tidal height. We may therefore expect crabs that are more risk-averse to inhabit areas higher on the shore and crabs that are more risk-tolerant to inhabit areas lower on the shore. Alternatively, crabs lower on the shore that are exposed to predator cues more consistently may simply become acclimated to these cues and so respond less strongly. In either case, it follows that we may expect resulting TMII strength to differ spatially throughout oyster reefs as a result of this spatial difference in crab behavioral response. To test this, we collected crabs haphazardly in high and low shore areas by removing oyster clusters and capturing all large crabs that were present (crab size range: $30.1-39.0 \mathrm{~mm}$ carapace width). High areas were defined as areas of the oyster reef that were exposed daily during semidiurnal low tides throughout the monthly tidal cycle (and where crabs were sampled that were used in the portions of this study described above), whereas low areas were defined as the lowest regions of the oyster reef that could be accessed by monthly spring tides, but that were normally under water at all times except during extreme tides (evidenced by the presence of abundant sponges). We will refer to high and low sites as intertidal and subtidal, respectively. Intertidal and subtidal sites for collection were adjacent to each other, separated by approximately $1.5 \mathrm{~m}$ vertically. For each crab that was collected ( $n=15$ from each tidal height), we repeated the experiment described above that was used to assess proportion of time spent in refuge use in the presence and absence of predator risk cues. We again used Pearson's correlation to test for consistent behavior type in the presence and absence of risk cues. We did this separately for subtidal and intertidal crabs. For each of these two groups, we then used linear models with a binomial error distribution to examine the influence of crab size on refuge use by crabs in the presence and absence of risk cues (use of mixed models was again prohibited by overdispersed binomial data for the reason described above). We then determined whether there were overall behavioral differences between subtidal and intertidal crabs by comparing refuge use in the absence of risk cues for these two groups using a $t$ test. Finally, we used separate paired $t$ tests for subtidal and intertidal crabs to examine the change in refuge use in the presence and absence of risk cues. Our analysis determines whether behavioral responses to predation risk vary for subtidal and intertidal crabs, but does not differentiate between the alternative possibilities of habitat choice vs. habituation that may mechanistically cause spatial differences in behavioral responses.

\section{Results}

\section{Refuge use in the presence and absence of predator cues}

There was a large amount of individual variation in the proportion of time that crabs spent in the refuge rather than actively foraging outside of oyster shell refuges. This variation was persistent within crabs in the absence (range of proportion of time in refuge: $0.06-1$ ) and in the presence (range of proportion of time in refuge: $0.1-1$ ) of predator risk cues (Pearson's correlation, rho $=0.47$, Fig. 1). On average, refuge use was $52 \%$ $\pm 8 \%$ greater in the presence of predator risk cues than when risk cues were absent (Fig. 2). Further, the proportion of time spent in oyster shell refuge decreased with crab size, both in the presence $(t=-2.65, P=0.011$, Fig. 2) and in the absence of risk cues $(t=2.706, P=$ 0.009, Fig. 2).

\section{Effect of behavioral variation on TMII}

We found that individual variation in oyster shell refuge use (as reported in the experiment from the previous section) and the presence of a predator risk cue 


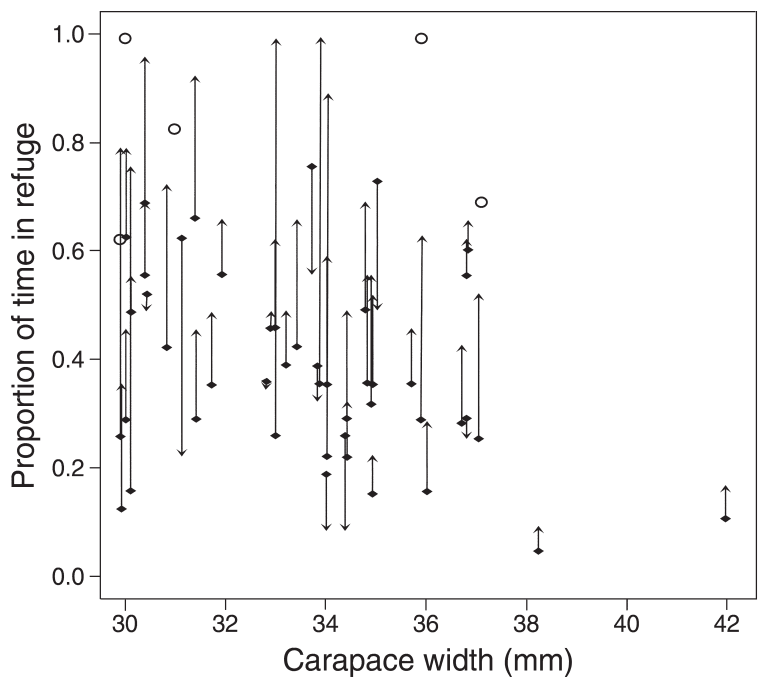

FIG. 2. Proportion of time spent in refuge as opposed to actively foraging as a function of crab carapace width and in the presence and absence of predator risk cues. Each line represents single crab, starting with diamond at time in refuge in absence of predator and ending in arrow at proportion of time in refuge in presence of predator. The length of the arrow therefore reflects the magnitude of behavioral shift for each crab. Circles are individuals that spent same time in refuge regardless of predator presence/absence.

interacted to determine the number of mussels consumed (mixed effect model interaction term, $z=-2.1, P$ $=0.036$, Fig. 3). We therefore repeated the analyses separately (generalized linear models) for consumption with and without predator risk cues to improve clarity of interpretation regarding the influence of individual variation in refuge use. Within the relatively small size range of crabs used in this experiment $(30-42 \mathrm{~mm}$ carapace width), we found that allometric scaling of consumption rate was induced by the presence of predator risk cues. Specifically, we found that in the absence of predator risk cues, prey consumption by crabs was not influenced by crab size $(z=-0.79, P=$ $0.43)$ or by refuge use $(z=0.049, P=0.96$, Fig. 3). However, when predator risk cues were present, consumption of mussels by mud crabs was positively correlated with crab size (estimate $\pm \mathrm{SE}=0.04 \pm 0.02$ mussels $/ \mathrm{mm}$ carapace width, $z=2.52, P=0.01$ ) and was inversely correlated with the proportion of time that individual crabs spent in refuge use during the experiment described in the preceding subsection, though this effect was not significant at the $\alpha=0.05$ level (estimate \pm $\mathrm{SE}=-0.33 \pm 0.19, z=-1.69, P=0.091$, Fig. 3). (The full model output from the mixed effects model is given in the Appendix.) Therefore, the effect of crab size on mussel prey consumption in the presence but not in the absence of predator risk cues likely resulted from greater refuge use by smaller crabs when risk cues were present (i.e., crab size and refuge use covaried, Fig. 2). The nonsignificant effect of amount of time spent in refuge on mussel consumption in the presence of risk cues therefore reflects only aspects of individual behavior type that were not already accounted for by crab size.

\section{Behavior type and distribution in the field}

For mud crabs collected in adjacent intertidal and subtidal areas, refuge use by individual crabs in the absence and presence of predator risk cues was consistently correlated for both groups (intertidal crabs rho $=0.52$, subtidal crabs rho $=0.43$ ). Refuge use was not influenced by crab size for either subtidal or intertidal crabs in the presence or in the absence of risk cues (all $P>0.05$ ). However, the two groups differed in the distribution of their behavior types (Fig. 4). Specifically, refuge use was greater in intertidal than in subtidal areas ( $t$ test comparing refuge use in absence of risk cues, $t=2.027, P=0.05$, Fig. 5). The change in refuge use when predator risk cues were absent or present differed for the two groups. Refuge use was greater in the presence than in the absence of predator risk cue for intertidal crabs (paired $t$ test, $t=-2.34, P=$ 0.032 , Fig. 5), but not for subtidal crabs (paired $t$ test, $t$ $=-0.55, P=0.59$, Fig. 5). There was no difference in size of crabs sampled from the two areas ( $t$ test, $P=0.64$ ).

\section{Discussion}

Results here suggest that individual trait variation may be useful in predicting the strength of indirect effects in food webs. Previous work demonstrated that the mud crab Panopeus herbstii reduces its foraging effort in the presence of predation cues from toadfish, and that this has positive indirect benefits for bivalve survival (Grabowski 2004, Grabowski and Kimbro

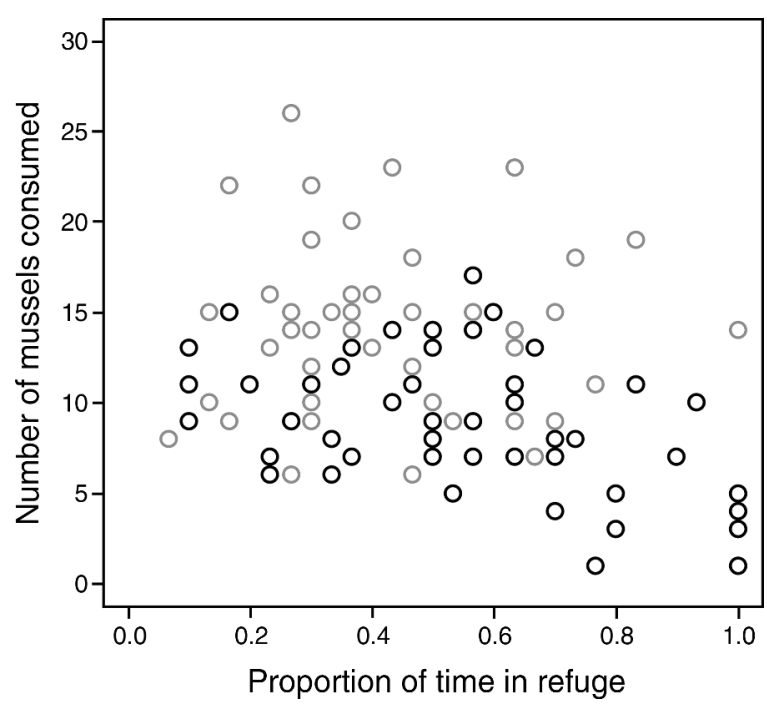

FIG. 3. Number of mussels consumed by mud crabs in the presence (black circles) and absence (gray circles) of predator risk cues as a function of time spent hiding in oyster shell refuges as determined in the experiment shown in Fig. 3. 

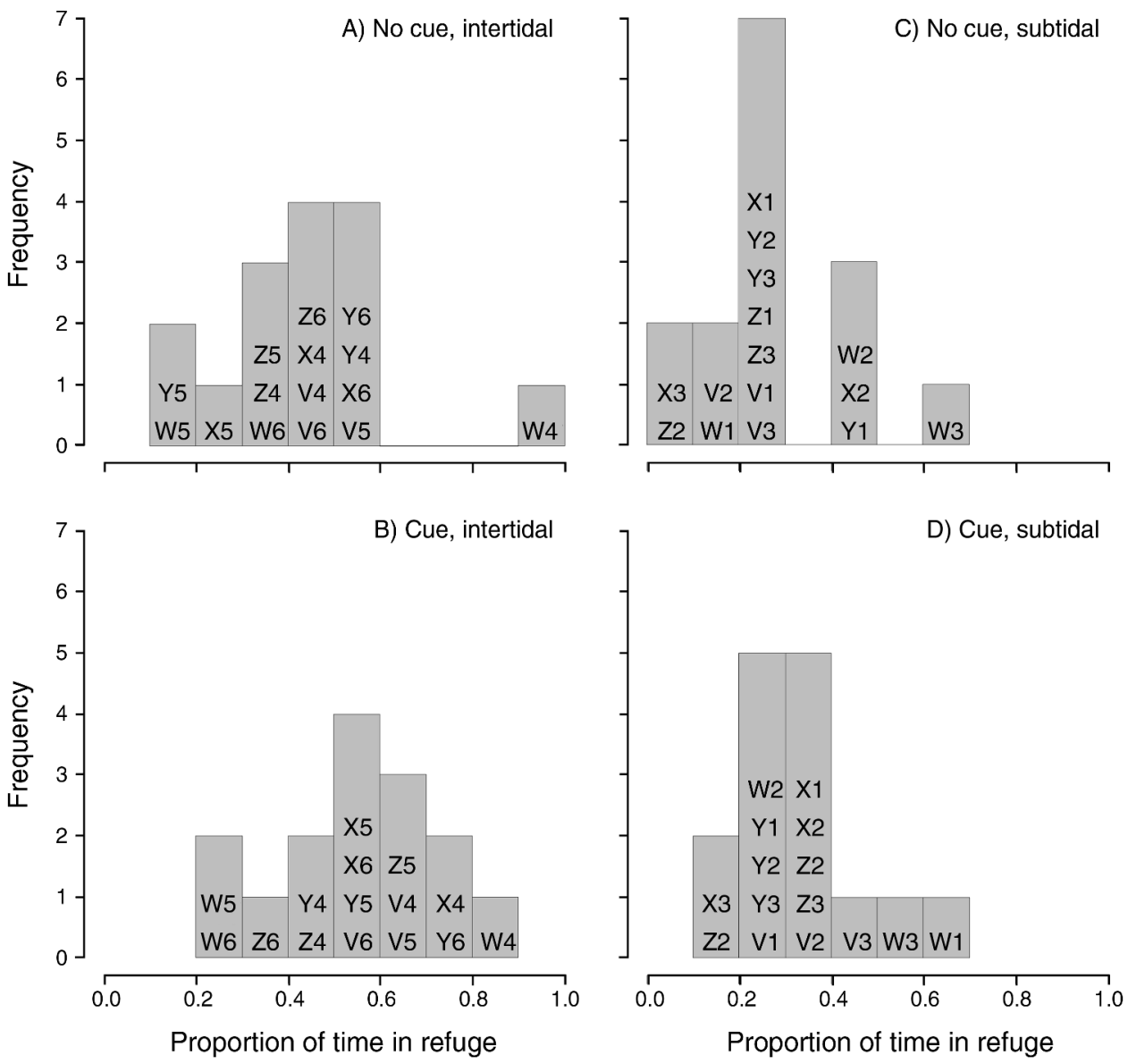

FIG. 4. Frequency distribution of refuge use by intertidal and subtidal crabs in the absence and presence of predator risk cues. Letter-number codes in each bar are assigned ID numbers for individual crabs.

2005, Grabowski et al. 2008). We have shown that the strength of this effect differs between mud crabs, both with the size of the mud crab (the smaller the crab, the larger the indirect effect) and with the personality or behavior type of the crab. Crabs displayed a wide range of variation in proportion of time that they spent hiding vs. foraging in the presence of predator risk cues, and the more time that crabs spent hiding, the stronger was the indirect benefit of toadfish on mussel survival. The distribution of behavior types within a population may therefore be a useful tool for predicting the strength of TMII under field conditions where numerous individuals with a range of behavior types occur together. The experimental results reported here are in direct agreement with conceptual predictions posited in a recent review of on the ecological importance of behavior types (Sih et al. 2012). Our results further suggest that the distribution of behavior types at a single tidal height in our study system is determined to some extent, though not entirely, by crab size. Aggression in crabs is often correlated within individual body size (Brown et al. 2005). This is likely because the principal weapon of crabs, the claw, change allometrically in both strength and dexterity with carapace width for $P$. herbstii as well as for other species (Schenk and Wainwright 2001).

Our results also suggest that the strength of TMII may vary spatially as a result of spatial variation in the distribution of behavior types. Specifically, we demonstrated a clear difference between behavior types according to the tidal height where crabs were collected at low tide. This difference was not an artifact of crab size, as no difference in size of sampled crabs existed between the two tidal heights. Subtidal individuals spent less time than intertidal crabs in refuge use overall and were relatively unresponsive to predator risk cues, suggesting either that crabs that are more risk prone move to subtidal habitats where feeding is interrupted much less frequently by daily tides, or that crabs in subtidal areas become conditioned to the presence of predator risk cues and so respond less strongly to these cues. The following arguments support the first of these options. In the absence of predation risk, mud crabs generally come out of oyster reef crevices to forage on and around the shells of oyster reefs during high tide 
(Grabowski 2004; B. Griffen, personal observation). Further, mud crabs are relatively mobile. Stachowicz and Hay (1999) conducted a relocation study of released $P$. herbstii to determine the distance that crabs traveled in $48 \mathrm{~h}$. Crabs that were relocated traveled $1 \mathrm{~m}$ on average, but the majority of crabs were not recovered within a $5 \mathrm{~m}$ radius of the release point, suggesting that they had moved $>5 \mathrm{~m}$ in $48 \mathrm{~h}$. Our subtidal and intertidal sampling sites were separated by $1.5 \mathrm{~m}$ of tidal height, reflecting a relatively short linear distance along the banks of steep tidal creeks. Individual crabs may therefore readily traverse this distance on a single day. Data presented here indicate that behavioral responses of individuals remain relatively constant at least over 24$\mathrm{h}$ periods. The combination of these facts suggests that our data reflect crab choices of refuge habitats based on personality type rather than habituation of crabs to different levels of risk cue at different tidal heights. This is consistent with theoretical predictions that prey with broad domains (i.e., mud crabs that are capable of moving throughout subtidal and intertidal habitats) should readily seek out safer habitats when cues from sit-and-pursue predators such as toadfish are present (Preisser et al. 2007). However, our data cannot rule out habituation.

Whether the spatial difference in response to risk cue is created by crab habitat selection according to behavior type, or by conditioning at lower tidal heights where cues are more prevalent, the implications for TMII in this system are the same. Specifically, assuming that crabs sampled at specific tidal heights during our low tide sampling remain at these heights during high tide foraging, which may or may not be the case, we should expect TMII to be stronger higher up in the intertidal due to the stronger response to predation risk of crabs in this area. Animal personality is a general phenomenon across taxonomic groups and encompasses a diversity of behavioral traits (Gosling 2001, Sih et al. $2004 a, b)$. Consequently, the effects described herein could operate in a wide variety of test systems.

Understanding variation in the strength of TMII, when and why it occurs, will improve our ability to understand complex ecological dynamics. This is particularly important in projecting the implications for ecological systems of environmental changes that result in the loss of biodiversity. Loss of biodiversity is manifested not only in species loss, but in the loss of intraspecific diversity (i.e., a decrease in intraspecific variation). For example, fish that are bold foragers consume more food and therefore grow more quickly to larger size. Fishing that selectively captures the largest fish in the population can therefore reduce intraspecific behavioral diversity by removing these bold individuals (Biro and Post 2008). It is therefore important to understand the implications of individual trait variation for propagating TMII in order to understand how the role of TMII as community-structuring forces may change with further reductions or modifications to the

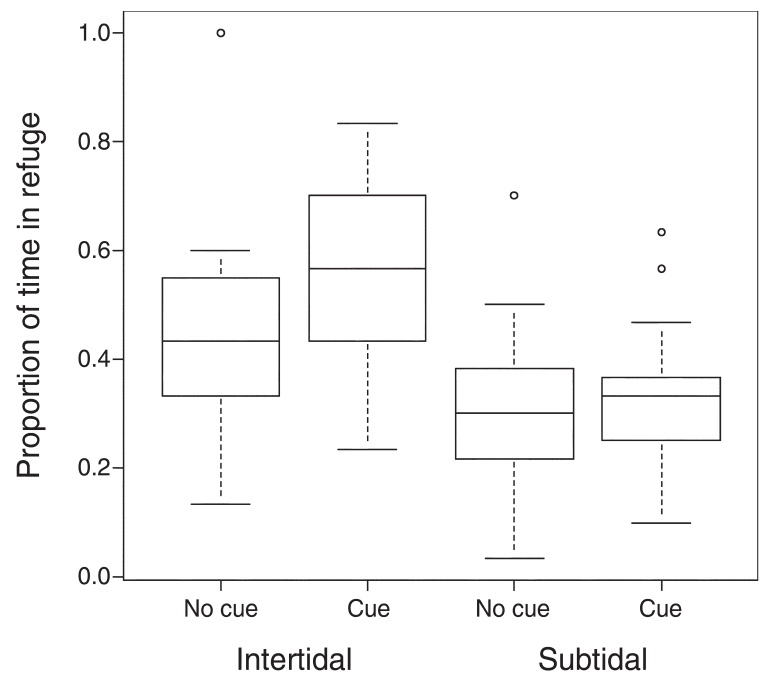

FIG. 5. Proportion of time spent hiding in oyster shell refuge in a laboratory experiment in the presence and absence of a predator risk cue, and as a function of location of crab collection, either in the intertidal oyster reefs or in an adjacent subtidal oyster reef. In box plots, the center line gives the median value; the bottom and top of box give the 25 th and 75 th percentile (or the interquartile range), respectively; whiskers give the extremes of the data that fall within 1.5 times the interquartile range of the data; circles give outliers, or data that fall more than 1.5 times the interquartile range away from the box.

level of individual variation. This is particularly true if, as in the fish example by Biro and Post cited previously, the reductions in intraspecific variation are directional. Directional biodiversity loss may be the expected norm if such losses are due to specific drivers rather than "nonpoint" sources of perturbation. Under directional loss of intraspecific biodiversity, the importance or strength of TMII may change in predictable ways.

\section{ACKNOWLEDGMENTS}

This work was supported by NSF grant number OCE1129166, by an NSF Graduate Research Fellowship under grant number DGE-0929297, and by a Magellan grant for undergraduate research by the University of South Carolina.

\section{Literature Cited}

Abrams, P. A. 2007. Defining and measuring the impact of dynamic traits on interspecific interactions. Ecology 88:25552562.

Anholt, B. R., and E. E. Werner. 1995. Interaction between food availability and predation mortality mediated by adaptive behavior. Ecology 76:2230-2234.

Bennett, A. F. 1987. Interindividual variability: an underutilized resource. Pages 147-169 in M. E. Feder, A. F. Bennett, W. W. Burggren, and R. B. Huey, editors. New directions in ecological physiology. Cambridge University Press, Cambridge, UK.

Biro, P. A., and J. R. Post. 2008. Rapid depletion of genotypes with fast growth and bold personality traits from harvested fish populations. Proceedings of the National Academy of Sciences USA 105:2919-2922. 
Bolker, B., M. Holyoak, V. Krivan, L. Rowe, and O. Schmitz. 2003. Connecting theoretical and empirical studies of traitmediated interactions. Ecology 84:1101-1114.

Bolnick, D. I., P. Amarasekare, M. S. Araujo, R. Burger, J. M. Levine, M. Novak, V. H. W. Rudolf, S. J. Schreiber, M. C Urban, and D. A. Vasseur. 2011. Why intraspecific trait variation matters in community ecology. Trends in Ecology and Evolution 26:183-192.

Bolnick, D. I., R. Svanback, M. S. Araujo, and L. Persson. 2007. Comparative support for the niche variation hypothesis that more generalized populations also are more heterogeneous. Proceedings of the National Academy of Sciences USA 104:10075-10079.

Bolnick, D. I., R. Svanback, J. A. Fordyce, L. H. Yang, J. M. Davis, C. D. Hulsey, and M. L. Forister. 2003. The ecology of individuals: incidence and implications of individual specialization. American Naturalist 161:1-28.

Brown, K. M., S. F. Keenan, and P. D. Banks. 2005. Dominance hierarchies in xanthid crabs: roles in resourceholding potential and field distributions. Marine Ecology Progress Series 291:189-196.

Careau, V., D. Thomas, M. M. Humphries, and D. Reale. 2008. Energy metabolism and animal personality. Oikos 117:641653.

Connor, M. M., and G. C. White. 1999. Effects of individual heterogeneity in estimating the persistence of small populations. Natural Resources Modeling 12:109-127.

Dieckmann, U., and M. Doebeli. 1999. On the origin of species by sympatric speciation. Nature 400:354-357.

Dingemanse, N. J., A. J. N. Kazem, D. Reale, and J. Wright. 2010. Behavioural reaction norms: animal personality meets individual plasticity. Trends in Ecology and Evolution 25:81-89.

Doebeli, M. 1996. A quantitative genetic competition model for sympatric speciation. Journal of Evolutionary Biology 9:893909.

Fox, G. A. 2005. Extinction risk of heterogeneous populations. Ecology 86:1191-1198.

Fox, G. A., and B. E. Kendall. 2002. Demographic stochasticity and the variance reduction effect. Ecology 83:1928-1934.

Gosling, S. 2001. From mice to men: what can we learn about personality from animal research. Psychological Bulletin 127:45-86.

Grabowski, J. H. 2004. Habitat complexity disrupts predatorprey interactions but not the trophic cascade on oyster reefs. Ecology 85:995-1004.

Grabowski, J. H., A. R. Hughes, and D. L. Kimbro. 2008. Habitat complexity influences cascading effects of multiple predators. Ecology 89:3413-3422.

Grabowski, J. H., and D. L. Kimbro. 2005. Predator-avoidance behavior extends trophic cascades to refuge habitats. Ecology 86:1312-1319.

Grabowski, J. H., and S. P. Powers. 2004. Habitat complexity mitigates trophic transfer on oyster reefs. Marine Ecology Progress Series 277:291-295.

Griffen, B. D. 2006. Detecting emergent effects of multiple predator species. Oecologia 148:702-709.

Griffen, B. D., and J. E. Byers. 2006. Partitioning mechanisms of predator interference in different habitats. Oecologia 146:608-614.

Griffen, B. D., and T. Williamson. 2008. Influence of predator density on nonindependent effects of multiple predator species. Oecologia 155:151-159.

Gudger, E. W. 1910. Habits and life history of the toadfish (Opsanus tau). Bulletin of the Bureau of Fisheries 28:10711099.

Kendall, B. E., and G. A. Fox. 2002. Variation among individuals and reduced demographic stochasticity. Conservation Biology 16:109-116.

Kendall, B. E., and G. A. Fox. 2003. Unstructured individual variation and demographic stochasticity. Conservation Biology $17: 1170-1172$.
Kerfoot, W. C., and A. Sih. 1987. Predation: direct and indirect impacts on aquatic communities. University Press of New England, Hanover, New Hampshire, USA.

Lomnicki, A. 1988. Population ecology of individuals. Princeton University Press, Princeton, New Jersey, USA.

Luttbeg, B., and J. L. Kerby. 2005. Are scared prey as good as dead? Trends in Ecology and Evolution 20:416-418.

Menge, B. A. 1995. Indirect effects in marine rocky intertidal interaction webs: patterns and importance. Ecological Monographs 65:21-74.

Preisser, E. L., D. I. Bolnick, and M. F. Benard. 2005. Scared to death? The effects of intimidation and consumption in predator-prey interactions. Ecology 86:501-509.

Preisser, E. L., J. L. Orrock, and O. J. Schmitz. 2007. Predator hunting mode and habitat domain alter nonconsumptive effects in predator-prey interactions. Ecology 88: 2744-2751.

Pruitt, J. N., J. J. Stachowicz, and A. Sih. 2012. Behavioral types of predator and prey jointly determine prey survival: potential implications for the maintenance of within species behavioral variation. American Naturalist 179:217-227.

R Development Core Team. 2011. R v.2.14.1. R Project for Statistical Computing, Vienna, Austria. www.r-project.org

Relyea, R. A., and K. L. Yurewicz. 2002. Predicting community outcomes from pairwise interactions: integrating density- and trait-mediated effects. Oecologia 131:569-579.

Rosenheim, J. A. 1998. Higher-order predators and the regulation of insect herbivore populations. Annual Review of Entomology 43:421-447.

Rosenzweig, M. L. 1978. Competitive speciation. Biological Journal of the Linnaean Society 10:275-289.

Schenk, S. C., and P. C. Wainwright. 2001. Dimorphism and the functional basis of claw strength in six brachyuran crabs. Journal of Zoology 255:105-119.

Schmitz, O. J., V. Krivan, and O. Ovadia. 2004. Trophic cascades: the primacy of trait-mediated indirect interactions. Ecology Letters 7:153-163.

Schmitz, O. J., and K. B. Suttle. 2001. Effects of top predator species on direct and indirect interactions in a food web. Ecology 82:2072-2081.

Sih, A., A. Bell, and J. C. Johnson. 2004a. Behavioral syndromes: an ecological and evolutionary overview. Trends in Ecology and Evolution 19:372-378.

Sih, A., A. M. Bell, J. C. Johnson, and R. E. Ziemba. $2004 b$. Behavioral syndromes: an integrative overview. Quarterly Review of Biology 79:241-277.

Sih, A., J. Cote, M. Evans, S. Fogarty, and J. Pruitt. 2012. Ecological implications of behavioural syndromes. Ecology Letters 15:278-289.

Sih, A., G. Englund, and D. Wooster. 1998. Emergent impacts of multiple predators on prey. Trends in Ecology and Evolution 13:350-355.

Stachowicz, J. J., and M. E. Hay. 1999. Reduced mobility is associated with compensatory feeding and increased diet breadth of marine crabs. Marine Ecology Progress Series 188:169-178.

Toscano, B. J., F. J. Fodrie, S. L. Madsen, and S. P. Powers. 2010. Multiple prey effects: agonistic behaviors between prey species enhances consumption by their shared predator. Journal of Experimental Marine Biology and Ecology 385:59-65.

Trussell, G. C., P. J. Ewanchuk, and C. M. Matassa. 2008. Resource identity modifies the influence of predation risk on ecosystem function. Ecology 89:2798-2807.

Vindenes, Y., S. Engen, and B. E. Sæther. 2008. Individual heterogeneity in vital parameters and demographic stochasticity. American Naturalist 171:455-467.

Werner, E. E., and S. D. Peacor. 2003. A review of traitmediated indirect interactions in ecological communities. Ecology 84:1083-1100.

Wilson, C. A., J. M. Dean, and R. Radtke. 1982. Age, growthrate and feeding-habits of the oyster toadfish, Opsanus tau 
(Linnaeus) in South Carolina. Journal of Experimental Marine Biology and Ecology 62:251-259.

Wilson, D. S., and M. Turelli. 1986. Stable underdominance and the evolutionary invasion of empty niches. American Naturalist 127:835-850.
Wissinger, S., and J. McGrady. 1993. Intraguild predation and competition between larval dragonflies: direct and indirect effects on shared prey. Ecology 74:207-218.

Wootton, J. T. 1994. The nature and consequences of indirect effects in ecological communities. Annual Review of Ecology and Systematics 25:443-466.

\section{Supplemental Material}

\section{Appendix}

A table of mixed effects model output to examine how refuge use, predator risk cue, and individual variation influenced mussel consumption (Ecological Archives E093-170-A1). 